\title{
The Underground Water Level Simulation in Imamzadeh Jafar Plateau by the Use of Mudflow Software
}

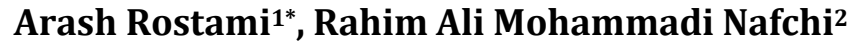 \\ ${ }^{1}$ Department of Civil Engineering, Yasouj Branch, Islamic Azad University, Yasouj, Iran \\ ${ }^{2}$ Chaharmahal and Bakhtiari, Agricultural and Natural Resources Research and Training Center, Chaharmahal \\ and Bakhtiari, Iran \\ Email: "rostamiarash2@gmail.com
}

Received 2 May 2016; accepted 19 August 2016; published 22 August 2016

Copyright (C 2016 by authors and Scientific Research Publishing Inc.

This work is licensed under the Creative Commons Attribution International License (CC BY). http://creativecommons.org/licenses/by/4.0/

(c) (†) Open Access

\begin{abstract}
The most secure method in providing water in the dry and semi-dry regions is the use of underground water sources and due to over consumption of water aquifers capacities, most of fields and specially Imamzadeh Jafar are faced with negative performance and balance, which threatens the land subsiding. The plateau with the annual raining of 438 millimeters has 169 deep and semideep wells with annual 36.68 million consumption and this issue has increased the research signification, in order to protect and relive the required water aquifers, there is a need to predict the underground water level accurately in different condition. In this research, by the use of balance equation and modflow software in Imamzadeh Jafar, water aquifer was analyzed within seven scenario. The underground water level evaluation for the short run periods for 2 years and middle term of 4 years and 12 years of long term was performed; and the results showed that the performance and balance of the plateau was increased due to increase of water consumption compared to the water aquifer quantity in the region that was negative. To the point that the $1,3,4,5,7$ scenarios (minimum 0.17 and maximum -11.34) and 2, 6 scenarios in different timely periods show that the underground water saving volume is positive (minimum 3.64 and maximum 19.83).
\end{abstract}

\section{Keywords}

Water Balance Equation, Modflow, Short Run Timely Periods, Medium Run Timely Periods, Long Run Timely Periods, Underground Water

\footnotetext{
${ }^{*}$ Corresponding author.
} 


\section{Introduction}

Iran is the land with semi dry climate and the average rainfall of 240 millimeter is equal to or even less than one third of average rainfall in the world, and from the other hand, the Iran annual evaporation rate is three times more than other part of earth [1]. In such condition, in order to response to water inquires and avoid negative performance and balance of aquifer, we should define and operate the aquifer water projects at national level. It is obvious that in this relation the necessity to perform the research projects at the field of water sources specially the prediction and evaluation of aquifer behavior is essential in addition to perform different scenarios.

Therefore, today the most save and simple and low cost method of water provision is the use of underground water.

[2] evaluated the artificial feeding effect on the sweat water displacement (interface) in Tasuj field by the use of underground water mathematical model, GIS system, and evaluation of region water balance, they concluded that the artificial feeding plan and flood distribution in the underground water have suitable influence. [3] simulated aquifer of Jahrom field in order to evaluate different operational options by the use of modflow numerical model and in addition to measure two parameters of hydraulic directing and saving coefficient and the output model evaluation, the aquifer stationary drop is assumed definitely in the future 10 years that the main reason in the drought period is the increase of water consumption rate from the operating wells and lack of wells territory obtaining.

[4] did a research with the title of operating development possibility from the available water sources in the aquifer of Kiyar field by the use of modflow model and calculation of water balance. Based on the result of this model and water balance and also the operational scenario for the water consumption from well, it was clarified that according to the available potentials, there was possibility to provide the water requirements of the region in order to increase the economical growth enhancement and it was suggested that a correct management plan was considered to control different strategies. [5] studied the Jiruft field underground water by the use of modflow model by the purpose if aquifer water level changes prediction and the results showed that according to the over consumption of underground water, the water level is reduced in most of piezometers and to come up with this condition there should be an attempt to reduce the aquifer consumption rate to make balance between the aquifer feeding and implementation. Lotfie and Mehrdad (2012) in their research by title of pumping parameters evaluation, feeding and evaporation and perspiration of water from the underground water level evaluated the conditions in Orumieh by the use of modeflow software and in this model the 38 wells water lever piezometer was used that evaporation parameters and pumping from operating wells and feeding of under evaluation and sensitivity was considered and the feeding parameter is recognized as the most effective factor in the underground water level and it was put in the second rate of pumping that evaporation and perspiration had the fewest effect and the results showed that by supplying the agricultural wells proper management and reducing the pumping in received water from the climate raining and directing them to the position that feeding could be used in the water level increasing. [6] performed a research by title of future condition prediction in Hashem well aquifer and by use of modflow software to realize the future condition of aquifer and proceeded to simulate the aquifer by the use of modflow software that the results in this research the agricultural well pumping parameters and hydraulic directing were considered as the most effective parameters in the aquifer model.

[7] simulated the underground water sources implementation in the draught condition with modflow by the use if the limited differentiation method issue and they concluded that to compensate the underground water level drop is according to the region water requirement there should be attempt to reduce the implementation of well water to $20 \%$ and by reduction of $20 \%$ of operation in water consumption to reduce the underground water level drop to -1.3 meter. evaluated the underground water in yum aquifer by the modflow model that in this research the underground water equality in the yum filed was simulated by the modflow software and the result showed that this model in the yum aquifer underground water the supplying main volume is from the river and the main discharge of water is due to such reason and the aquifer does not have the water level saving that by feeding in the rainy seasons and in dry weather it assist the aquifer. This research has shown the water saving importance. [8] evaluated the raining intensity effect on the underground water feeding in the simple declivity condition that the three dimensional model of underground water was used after the calibration and the underground water saving rates was analyzed for different raining intensity that by increase of raining intensity, the underground water feeding was reduced and the feeding coefficient was declared by the linear negative equation that $\mathrm{n}$ different modeling scenarios it showed that reduction in feeding rates and hydraulic heads is occurred simultaneously with the raining intensity increasing. Therefore in order to have accuracy and precision in under- 
ground water level prediction and the saved water quantity in aquifer by regarding different scenarios in order to optimize application based on the performed programing, this research was performed relatedly. The daily increase of need of oil company and also the Gachsaran city drinking water provision and number of villages and agricultural development and increased of request due to special condition in the region leads to the underground water level reduction in the under studying aquifer. This issue leads to different studying about such field.

\section{Methods and Study Area}

Imamzadeh plateau filed s located in 15 kilometers distance toward the east and north of Gachsaran city in Dogonbadan in coordinate of 51 degrees and 9 minutes to 50 degrees and 52 minutes in the east length and 30 degrees and 28 minutes to 30 degrees and 15 minutes in the north in the stature of 700 meters from the sea level and the raining average is 438 millimeters in the year and the annual temperature is 22.6 degree of centigrade and the annual average of evaporation is 3197 millimeter and the semi dry climate in 58 kilometers area in 15 kilometers distance to the east north of Gachsaran city.

The required information in the model includes the underground water level in observed wells annually and the excavated wells specification in the region ( the geographical condition, depth, owner and application type, flow and operation time and underground levels) and hydrodynamic coefficient of filed by the use of discovered wells pumping test and the operating values and the operation type from the water sources, related information to the topographic information of earth by the use of plans in 1:25,000 scales and the plateau wells specifications and the aquifer thickness and the bed stone changes by the use of geophysical studies and digging discovery wells around the aquifer through the geological plans, geophysical studying and excavation and related information to all water sources in the region were provided from the regional water company. finally the required information from the artificial network and modflow model was gathered and it was attributed to the model input then the model was assessed in the stable and passing condition and for all different conditions the validity and the feeding condition and operation method was selected to simulate the aquifer and by evaluation of different options effected, the operational options was used. This method has the field section, laboratory, software calculation and information processing and different plans preparation.

In order to evaluate the feeding rate and releasing the water sources and determination of changes in the Imamzadeh Jafar aquifer store volume, the water balance is used. The location of Imamzadeh filed was in the area of 58 kilometers in which 21 wells were observed in Figure 1 by the statistics and underground water information from 1997 in this area. The time duration for balance also is considered for 1 year from 2009 Mehr to 2010 Shahrivar. To determine the underground water balance by the use of balance criterions, the use of hydrological equation is inevitable.

$$
\Delta \mathrm{V}=\mathrm{Q}_{\mathrm{IN}}-\mathrm{Q}_{\mathrm{OUT}}
$$

$\mathrm{Q}_{\mathrm{IN}}$ : It is the total input of region aquifer,

$\mathrm{Q}_{\text {OUT }}$ : The total outputs of region aquifer,

$\Delta \mathrm{V}$ : Variation of underground water storage volume (negative, positive, zero).

The due feeding of artificial provision in the region is equal to 3.17 million cube meters and the feeding is done through the agricultural, industrial and drinking section water that is considered orderly in 25, 60, 60 percent.

The feeding rate has direct relation with fields flow in the plateau water basin and the field catchment is 162 kilometer in the mountain area. To calculate this feeding rate, 30 percent of annual raining has considered by Barati 1996. From the annual evaporation rate due to high level of underground water, more than 22 meter has been consumed, according to the presence of 169 active wells in the region, annually 36.7 million cube meters of water is consumed in the aquifer. By the use of hydrographic scale, the increase or decrease of storage volume is obtained (2009) Mehr and Sharivar (2010) and according to the filed average specific watering capacity that is 4 percent and the aquifer area, the changes volume of store is obtained. After the balance calculation of plateau in 2009-2011, the feeding rate and the discharge is regarded based on the meter in each day and the modflow model is considered for the input flow.

In the made network, according to the observed wells conditions, the located cells in the plateau are known as the active and out of area limit are known as the inactive cells. In the mentioned filed network, from 1200 cells, 479 cells are realized as the active cells and 721 cells are regarded as inactive cells (Figure 2), underground water primary information, based on the performed measurements, the piezometer wells water level has been con- 
sidered for the model input in the timely intervals in 2009 for the model calibration year as the model input.

\section{Imamzadeh Jafar Plateau Aquifer Conceptual Model}

The first level and one of the important sections in modeling is preparation of a conceptual model or development of model concepts. The conceptual model is the sample presentation of an image from the underground physical system by the use of topographical plans, geological information and region geophysical data and wells arrangement and piezometers and etc. the purpose of this model is preparation of conceptual model and simplify the complex condition that $s$ dominant in nature. The Imamzadeh Jafar plateau aquifer in the past sedimentation and new illuviation which are due to lime erosion beside the plateau and the shapes funnels that are located in the north and west north canyon neck that the basin stone of this aquifer in some ectopic limestone. Plateau

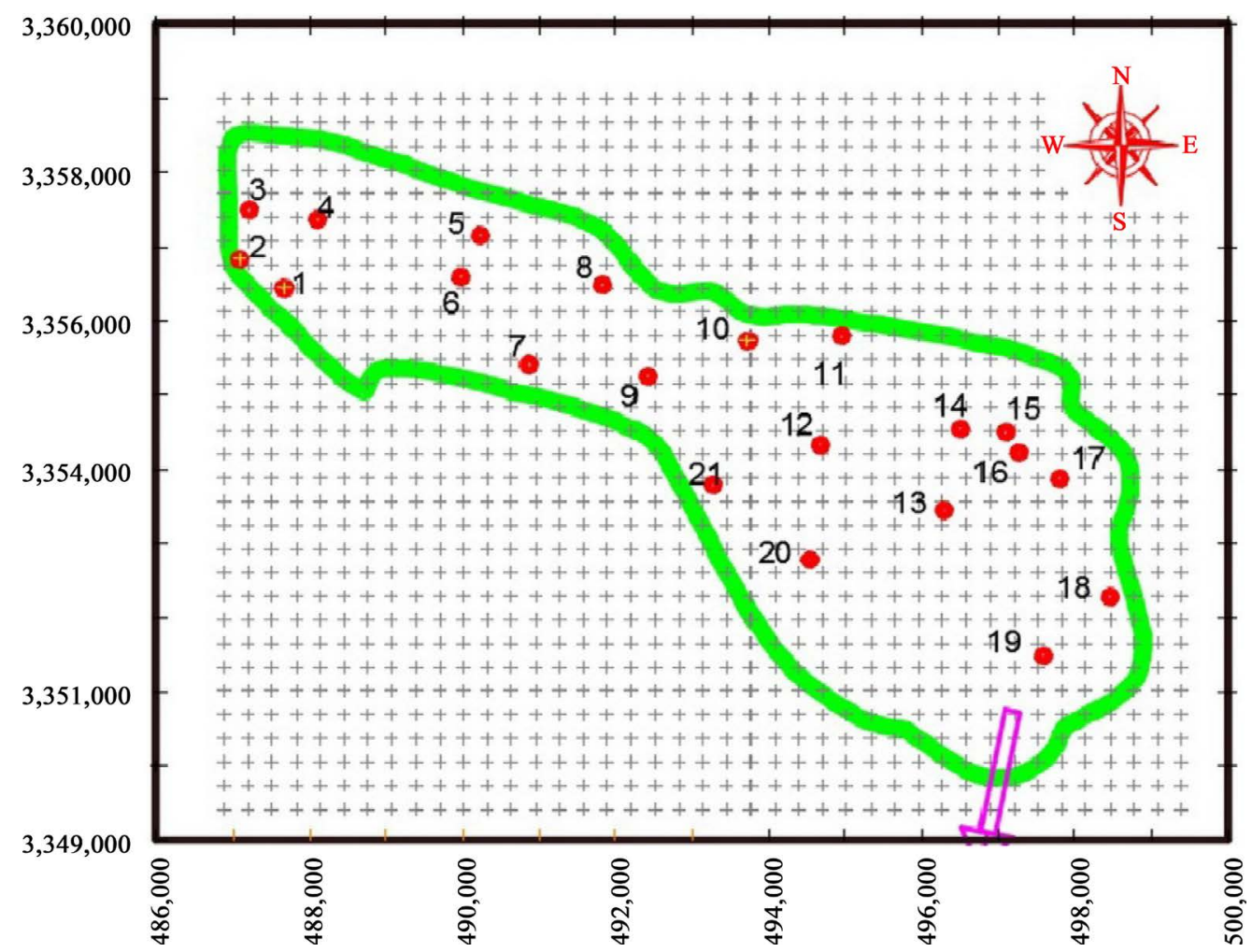

Figure 1. Network, boundary, the field output, the condition and number of piezometer in the plateau.

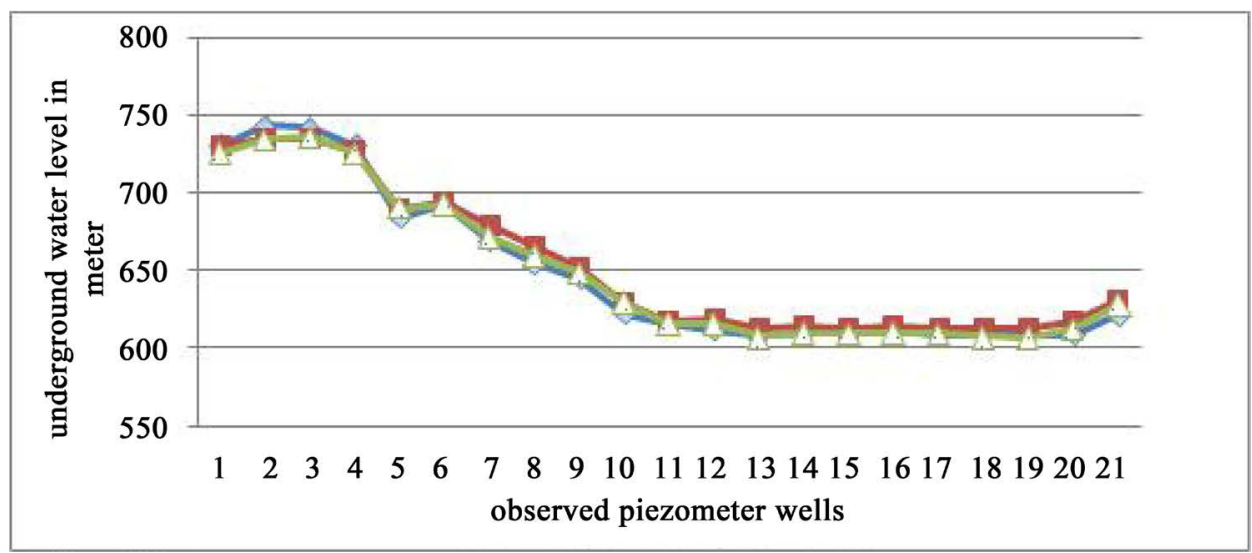

Figure 2. The comparison of plateau underground water by the use of observational statistics and calculations for Aban in 2013 and 2014. 
evaluation was identified that the thickness of field in this plateaus is increased from the north and the west north to the center area that it is increased to 220 meters in central sections and finally it is reduced to the south and east south (the surface water outlet) to lower than 20 meters and the registered information about the water level in recent 20 years has been used. Except number of seasonal streams that are derived from the north and west north and the permanent river does not exist in the area.

\section{Different Scenarios Operation}

The model that passes the assessment processes and validity evaluation will be suitable for the aquifer future condition and in this research according to the predicted condition for the future seven scenarios were analyzed as below.

The first scenarios: the operation has been considered with actual condition during 2009 to 2012.

The second scenario: transferring 11 million cube meters of water is reducing annually and some of agricultural wells are become inactive. As the result by transferring the water to the plateaus leads to water consumption reduction from the aquifer and a percent of transferred water is returned as the agricultural water wastewater again to the reservoir.

The third scenario: the water transferring from Zohreh River in 11 million cube meters to the plateau and increase of 17,500 hectares of agricultural fields to the region and fix consumption and normal condition is regard for the first scenario. The input water level to the plateau is returned to the reservoir again as the agricultural returned water that in this phase by increase of cultivation, only the agricultural wastewater is added to the aquifer and there is no changes to the aquifer consumption rate.

The fourth scenario: in this scenario the annual raining is reduced 30 percent for the drought and critical years and for the second scenarios condition (11 million cube meter water transferring annually and consumption reduction and fixation of under agriculture level and water consumption in the region has been operated in the model)

The fifth scenario: in this scenario the annual raining is reduced 30 percent ( for the drought and critical years and by the third scenario condition (11 million cube meters of water annually and the fix consumption and increase of under cultivation and water consumption in the region) the model was performed.

The sixth scenario: in this scenario the annual raining is increased 30 percent (for the wet conditions years and by the second scenario condition (11 million cube meters of water annually and the fix consumption and increase of under cultivation and water consumption in the region) the model was performed.

The seventh scenario: in this scenario the annual raining is increased 30 percent (for the wet conditions years and by the second scenario condition (11 million cube meters of water annually and the fix consumption and increase of under cultivation and water consumption in the region) the model was performed.

\section{Results}

In order to calibration of model in 35 monthly periods in instable conditions, the random and accidental method is used during 2009 to 2012. The result of modflow model calibration included the $98 \%$ coefficient and different volumes of hydraulic coefficient and the special watering was obtained 0.26 (meter in second) and 0.031 and after the calibration analysis results evaluation, the model sensitivity is identified that the made model had more sensitivity compared to tow other parameters to evaluate the model accuracy, the timely period between 2012 to 2014 has been considered. The result of evaluation about the model accuracy, the simulated water level volume was compared in two years from 2012 Aban to 2014 Aban and the correlation coefficient was shown about 99.

The results of model accuracy assessment in Aban 2013 and 2014 have been shown in Figure 1 that the results contained the $99 \%$ conformity that shows the proper performance. The result of first scenario for obtained results (operation with actual and real condition in years 88 to 91), which includes the water level reduction $-1 / 18$ meter for implementation with present condition, and the main reason of underground water is reduction of raining and over consumption of aquifer in recent year. Second scenario is operation with present condition and water transferring condition from Zohreh river and lack of under cultivation surface increasing and reduction of water consumption from aquifer to 11 million cube meter annually and increase of water level to 5.33 meter and in 1404 as the long run the water level will increase to +11.21 than the reason of underground water level is the inactivity of operating wells in providing the agricultural water from Zohreh river and feeding the region aquifer by agricultural wastewater. 
The third scenario (operation with present condition with water transferring condition from zohreh river and increase of 17,500 hectares of under cultivation lands in agricultural fields in Aban 2016 as the short term for the water level at -1.25 meter and in 2018 as the middle term the water level is -2.83 meter and in 1404 the long run period, the water level s reduced to -8.37 (Figure 2) that the reason of underground water reduction is the increase of cultivation and over consumption of underground water level. The result of fourth scenarios is that the annually raining reduced $30 \%$ for the drought condition with the second scenario condition (11 million cube meters of water transferring $n$ year and reduction of consumption and under cultivation fixation and the water consumption in region), based on the modflow model results in Aban 2016 as the short term, the water level is -1.30 and in 2018 as the middle term, the water level is -2.90 meter and for 1404 as the long term the water level is -8.54 which shows reduction and the main reason of underground water level is the annual raining reduction and increase of cultivation level and over consumption of underground water (Figure 3).

The results of modflow for the fifth scenario as the annual raining is reduced $30 \%$ and the 11 million cube meter transfer Nance annually and the consumption fixation and increase of water consumption n region declares that in Aban 2016 as the short term, the water level is reduced -2 meter and in 2018 as the middle term the water level is reduced -4.07 meter and in 1404 as the long term the water level s reduced -11.37 meters that the main reason is annual raining reduction and low feeding of aquifer. In six scenario the annual raining is increased 30 percent and the 11 million cube meters water transferring annually and reduction of consumption and fix underground cultivation and regional water consumption at the end of Aban 2016 as the short term the water level is +5.8 meter and in 2018 as the middle period the water level is +8.93 meter and in 1404 as the long term the water level is increased to +19.83 meters that the reason of underground water level increase is the raining acceleration, agricultural water provision from Zohreh river and underground water feeding by the agricultural wastewater. For the seventh scenario the annual raining is increased $30 \%$ for the wet condition and transferring 11 million cube meters annually and fixation of consumption and increase of underground water and consumptions in the region and it is predicted that in Aban 2016 as the short term, the water level is reduced to -0.17 meter and in 2018 as the middle term the water level is reduced to -0.60 meter and in 1404 as the long term period the water level s reduced to -2.14 meter that the main reduction reason is the feeding rater and raining volume reduction (Table 1).

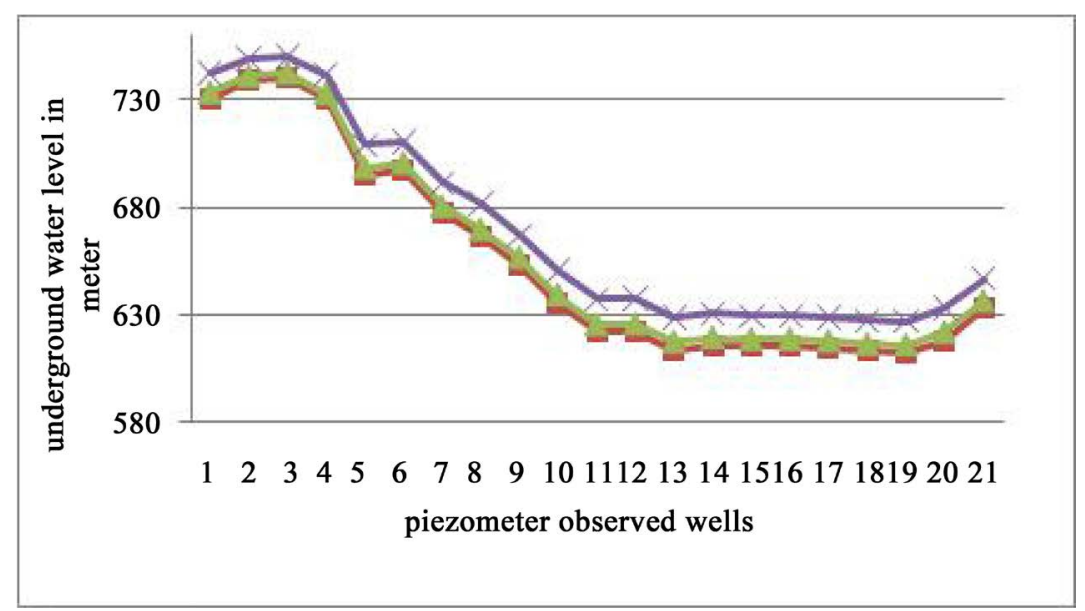

Figure 3. Underground water level comparison by the use of calculating and observing for 2016, 2018, 1404.

Table 1. The results obtained from defined scenarios in modflow model.

\begin{tabular}{cccc}
\hline \multirow{2}{*}{ Scenario number } & \multicolumn{3}{c}{ Predicted water level variation in meter } \\
\cline { 2 - 4 } 1 & Short term in meter Aban 2016 & Middle term in meter Aban 2018 & Long term in meter Aban 1404 \\
2 & -1.18 & 5.33 & 11.21 \\
3 & 3.64 & -2.83 & -8.37 \\
4 & -1.25 & -2.90 & -8.54 \\
5 & -1.30 & -4.07 & -11.34 \\
6 & -2 & 8.93 & 19.83 \\
7 & 5.8 & -0.6 & -2.14 \\
\hline
\end{tabular}




\section{Discussion and Conclusion}

Imamzadeh plateau is considered as cultivate field which has the aquifer and it is used as the industrial and agricultural and drinking water for the region that has caused high drop of underground water in aquifer by over consumption of alluvial reservoir, especially by the oil company and transferring to external region; middle reduction about 1.5 meter annually in this research as the water balance in 89 - 90 shows the water reduction to 6.7 million cube meters and in $90-91$ is about -0.34 million rate compared to 1996 with positive balance for 2.26 million cube meter which does not show the proper condition, and the general process of hydrograph in the plateau has the reduction process. Also the discharge from wells in industrial, agricultural and drinking sections has the main role in water discharge from underground water for about 36.6 million cube meter that leads to diminution of aquifer underground water level reduction. In the first scenario, the water level is reduced to 1.18 meter and for the third and fourth scenarios for the short term periods and also middle and long terms, the water level drop is considered but in the second scenario, due to inactivity of operating wells, the agricultural water provision from Zohreh river and feeding underground water through agricultural wastewater have caused the increase of water to +12.34 meter in Aban 2025 as the long run and for fifth and sixth scenarios, due to over consumption from the annual feeding volume, underground water level is reduced again but in seventh scenario in Aban 2016 as the short term the water level is increased to +5.8 and in 2018 as the middle period the water level is reduced to 8.93 and in 1404 as the long run period the water level will reduced to +19.83 that the main reason of underground water increasing is the raining enhancement and providing the agricultural water from rivers Zohreh and underground water feeding is dozen through the agricultural wastewater, according to the obtained results from the under studying field, there is a need to unite the management by comprehensive and long run program and long rum operational support.

\section{References}

[1] Asady, R.K. (2013) The Prediction about the Espekeh Aquifer Future Condition by the Use of Modflow. The Civil Engineering National Congress, Iran, 2013, 22.

[2] Azary, S. and Sabery, H. (1995) Evaluation of Operational Possibility Development in Water Sources Available in Kiyar Filed Aquifer by the Use of Modflow and Balance Calculation. The Iran Geology Congress, Iran, 1995, 63.

[3] Mehdi, Z. (2004) The Artificial Network and Applications in Civil Engineering. Technical Supreme Training Center, Tabriz.

[4] Pourhaqhie, M. (2014) The Operational Management from the Underground Water Sources in Drought Condition by Modflow Model. Case Study in Nourabad.

[5] Pursaidy, K. (2012) As the Underground Condition Study in Jifut Field by the Use of Mudflow.

[6] Zavareh, M. (2006) Lime Natural Nutritional Assessment with a View to the Effects of Artificial Recharge Aquifers Using MODFLOW Model and GIS (Case Study Tasuj Plain). Case Study for M.S. Thesis.

[7] Wang, H. and En Gao, J. (2015) Effects of Rainfall on Ground Water Recharge Based on Simulated Rainfall Experiments and a Groundwater Flow Model.

[8] Ziya, J. (2006) Simulation Arranged Aquifer Using Numerical Model MODFLOW. Iran, 88. 


\section{Submit or recommend next manuscript to SCIRP and we will provide best service for you:}

Accepting pre-submission inquiries through Email, Facebook, LinkedIn, Twitter, etc.

A wide selection of journals (inclusive of 9 subjects, more than 200 journals)

Providing 24-hour high-quality service

User-friendly online submission system

Fair and swift peer-review system

Efficient typesetting and proofreading procedure

Display of the result of downloads and visits, as well as the number of cited articles

Maximum dissemination of your research work

Submit your manuscript at: http://papersubmission.scirp.org/ 